\title{
La emergencia de enfermedades infecciosas
}

Bernardino Fantini

Traducción de del francés al español de Rodrigo Zapata Cano

Universidad de Antioquia

jose.zapata@udea.edu.co

El 5 de junio de 1981, el Center for Disease Control (CDC) de Atlanta, en Estados Unidos, publicó en su boletín semanal el primer anuncio oficial de una "nueva" enfermedad que se volvería algunos meses más tarde el sida o síndrome de inmunodeficiencia adquirida. El boletín describe cinco casos de neumonía grave con Pneumocystis carinii observados entre octubre de 1980 y mayo de 1981 en tres hospitales de los Ángeles. La particularidad "inhabitual", según el término de la noticia, reside en la aparición de la neumocistosis en cinco individuos "anteriormente sanos y sin signos clínicos de inmunodepresión". En este primer artículo ya se sugiere "la posibilidad de una disfunción de la inmunidad celular [...] que predispone a los individuos a las infecciones oportunistas, como la neumocistosis y la candidiasis" (Centers for Disease Control, 1981, pp. 250-252).

En este corto artículo de epidemiología encontramos el acta de nacimiento de una grave pandemia, pero también el punto de partida de una de las más grandes aventuras científicas y médicas del siglo XX. La aparición de la nueva epidemia de sida, enfermedad metafórica de la época "posmoderna" (Sontag, 1990), ha golpeado la sensibilidad de nuestra época y ha asustado tanto al mundo científico como a la opinión pública. La aparición de esta pandemia ha mostrado cruelmente que las enfermedades infecciosas todavía podían ser causas importantes de morbilidad y mortalidad.

La emergencia del sida (exactamente en el momento en que la OMS anunciaba la primera erradicación de una importante enfermedad infecciosa, la viruela) y al mismo tiempo que la reemergencia de otras endemias o epidemias que

Cómo citar: Fantini, B. (2021). La emergencia de enfermedades infecciosas (R. Zapata, trad.). Ciencias Sociales y Educación, 10(20), 299-311. Doi: https://doi.org/10.22395/csye.v10n20a14

Traducción realizada por Rodrigo Zapata Cano del artículo de Fantini (1999), "L'émergence de maladies infectieuses".

Agradecemos a la Revue médicale de la Suisse romande permitir la publicación del texto de Fantini en su versión en español en nuestra revista.

Recibido: 17 de julio de 2021.

Aprobado: 4 de agosto de 2021. 
habíamos creído que se podían erradicar, como el paludismo o la tuberculosis, ha constituido una verdadera sorpresa para las organizaciones sanitarias nacionales e internacionales. La palabra que se encuentra con más frecuencia en las publicaciones de esta época y los documentos oficiales de la OMS es "desafío", el reto de las nuevas enfermedades.

Esta sorpresa era la consecuencia del optimismo excesivo propagado en los medios médicos durante los años cincuenta y sesenta. En efecto, los desarrollos de la medicina y la farmacología habían dado la impresión de que las poblaciones estaban en lo sucesivo al abrigo de accesos epidémicos de enfermedades infecciosas. La espectacular caída de las enfermedades infecciosas, en particular la regresión de la tuberculosis, enfermedad metafórica y dominante del siglo XIX y de la primera mitad del XX, sobre todo en los países occidentales, como la erradicación del paludismo de algunos países templados, habían hecho nacer la esperanza de controlar por completo las enfermedades infecciosas. Incluso en presencia de las diferentes epidemias de gripa y del acceso epidémico de la poliomielitis, la posibilidad de nuevas enfermedades infecciosas en realidad no se tomaba en cuenta, debido a la euforia provocada por los éxitos obtenidos contra las enfermedades transmisibles gracias a los antibióticos y al DDT. Un cierto malestar fue percibido solamente por los escritores, en particular por los autores de ciencia ficción y por astrónomos que especulaban sobre la llegada de nuevas enfermedades del espacio (Hoyle y Wickramasingh, 1979).

A medida que las más importantes enfermedades infecciosas desaparecían de la lista de las diez primeras causas de mortalidad en los países industrializados, para ser reemplazadas allí por enfermedades llamadas de degeneración o de la civilización (cáncer, enfermedades cardiovasculares, enfermedades del metabolismo, accidentes y enfermedades crónicas), la idea de los responsables de la salud pública a nivel nacional e internacional era que, gracias a la inmunización en masa, la protección sanitaria, las buenas condiciones de vida, la mejor alimentación y el aprovisionamiento de agua de mejor calidad, las enfermedades infecciosas se debían volver cada vez más raras.

Por ejemplo, Macfarlane Burnet (1953) escribía:

Las enfermedades infecciosas siempre estarán presentes y siempre habrá lugar para el mejoramiento de la prevención y el tratamiento. Pero, perderán relativamente su importancia como la mayor causa de decesos en los años de la juventud y la madurez [...]. Creo que, gracias a las políticas de prevención existentes, de tratamiento médico y de producción de medicamentos, la investigación fundamental sobre los microorganismos y las enfermedades producidas, estas últimas se podrían detener sin influenciar el proceso en curso que está en camino de hacer desaparecer las principales enfermedades infecciosas, excepto la poliomielitis [...]. Es extre- 
madamente improbable que sean necesarios nuevos principios para mantener el actual control tan eficaz sobre las enfermedades infecciosas. (pp. 103-108)

Esta idea se ha reforzado ulteriormente con el descubrimiento de vacunas eficaces y seguras contra la poliomielitis (la enfermedad infecciosa paradigmática de los años cincuenta y sesenta en los países desarrollados). A finales de los años sesenta, en varias oportunidades se había planteado una pregunta: "Infectious disease, does it still matter?" ["Enfermedad infecciosa ¿todavía importa?"] (Howie, 1968, pp. 253-260), aun cuando la respuesta hubiera sido positiva ("sí, las enfermedades infecciosas todavía son importantes"), incluso el hecho de que la pregunta haya sido planteada, demuestra la manera de considerar la política de salud pública en los países desarrollados. Todavía en 1977 Beveridge (1977) escribía una excelente obra sobre la historia de la gripa que llevaba un título paradójico en la actualidad: Influenza, the last great plague [La gripa, la última gran peste].

En un libro magistral dedicado a la historia del sida, el historiador de la medicina Mirko D. Grmek se interroga sobre las causas biológicas, ecológicas y sociales de esta imprevista peste.

En sentido estricto, el sida no es una enfermedad nueva, pues el virus, como lo demuestra el análisis genético de las cepas, existía desde hacía mucho tiempo oculto detrás de "la pantalla" de otras enfermedades infecciosas. En el pasado, el virus VIH solo podía asegurar su supervivencia gracias a una "estrategia de parasitismo silencioso", puesto que, debido al dominio de las enfermedades infecciosas y de la limitación de las vías de transmisión, "una cepa muy virulenta no tenía ninguna oportunidad de perpetuarse por numerosos pasos sucesivos y provocar así una epidemia mortífera" (Grmek, 1989, p. 261). Una cepa virulenta habría podido provocar un foco local, que pasaría desapercibido a la mirada médica, oculta, por ejemplo, detrás de una forma violenta de tuberculosis o neumonía y que sería apagado a causa justamente de su violencia.

El desarrollo histórico o actual de una pandemia, y en particular la emergencia de una nueva enfermedad, se puede interpretar en su dinamismo gracias al concepto de "patocenosis", introducido por Grmek (1969), por analogía con el concepto biocenosis. En una población dada, las diferentes enfermedades están en equilibrio entre ellas, pues la frecuencia de cada enfermedad depende de la de las otras, con un número muy restringido de enfermedades dominantes y una cantidad mucho más importante de enfermedades relativamente raras. Podemos decir que las enfermedades infecciosas son antagonistas de las enfermedades degenerativas pues matan (o mataban, para los países occidentales), antes que los individuos puedan alcanzar la edad donde se manifiestan enfermedades como el cáncer o el alzhéimer. Entre las enfermedades presentes en 
una población dada hay un equilibrio históricamente determinado, que puede cambiar debido a modificaciones biológicas (un nuevo germen o un cambio de hospedero de un germen existente), sociales (los movimientos de población, por ejemplo) o ecológicos (la entrada en nuevos ecosistemas o la modificación de las técnicas de producción).

El siglo XX se puede considerar como una verdadera ruptura del equilibrio patocenótico, semejante a la introducción de la agricultura en el neolítico, a las migraciones de la Edad Media o al descubrimiento de América en el Renacimiento. Esto se debe a la unificación microbiana del mundo, a la globalización y la facilidad de los contactos entre poblaciones y diversos ecosistemas. Una pandemia es el resultado de la interacción entre factores biológicos y socioecológicos. La ruptura de un equilibrio preexistente produce consecuencias inesperadas. Esta ruptura puede tener tres causas principales:

a) La mutación de un virus o la recombinación entre gérmenes diferentes que produce un nuevo germen más virulento, a causa de su novedad.

b) Cambios sociales o ecológicos que producen nuevas condiciones favoreciendo focos epidémicos.

c) La apertura de nuevas vías de transmisión que permiten la difusión de un germen más allá de su nicho ecológico tradicional.

En el siglo XX, la aparición de enfermedades infecciosas nuevas está paradójicamente ligada a la vez al desarrollo científico y económico y a la pobreza de una gran parte de las poblaciones humanas. Esta pobreza impide el establecimiento de políticas de salud pública eficaces. Las mutaciones sociales (migraciones, urbanizaciones, cambios del comportamiento sexual y mezcla de las poblaciones) le han permitido al virus del sida franquear el umbral crítico que limitaba sus vías de transmisión. En efecto, hay una relación, que resulta de un equilibrio biológico, entre transmisibilidad y virulencia de un germen. Solo las vías de transmisión muy amplias, que aumentan el número de personas susceptibles de ser afectadas, pueden permitir la supervivencia biológica de un virus muy virulento. Un modelo de la relación entre virulencia y transmisibilidad ha sido desarrollado por Anderson y May (1992). Debido a sus técnicas y eficacia terapéutica, la medicina moderna ha producido una ruptura de la patocenosis suprimiendo las enfermedades infecciosas que ocultaban el sida y facilitando la transmisibilidad del virus, sobre todo por la apertura de la "vía de la sangre" (transfusiones, inyecciones, etc.). 


\section{El precedente de la poliomielitis}

Nuestro siglo ya había conocido una enfermedad emergente: la poliomielitis. Esta enfermedad, aunque muy antigua, conoció un acceso epidémico a finales del siglo XIX (Organisation Mondiale de la Santé, 1955). Después de la Segunda Guerra Mundial, este acceso se había vuelto una verdadera "marea creciente", para utilizar la expresión de Stowman (1947, p. 114).

La transformación de la parálisis infantil del siglo XIX, enfermedad relativamente rara, en poliomielitis epidémica, que hacía estragos en casi todo el mundo, plantea uno de los problemas de salud pública más angustiantes. Como para el sida en la actualidad, lo que era inquietante no era solo que la forma paralítica de la poliomielitis se volvía cada vez más frecuente y se extendía a regiones que se creían antes indemnes, pues esta frecuencia era casi por doquier claramente menos fuerte que la de muchas otras enfermedades infecciosas. Era sobre todo que no se conocía ningún método de lucha contra la enfermedad y que, paradójicamente, golpeaba más en los países donde las medidas de higiene y profilaxis contra la diseminación de las infecciones intestinales habían sido más rápida y eficazmente aplicadas.

Como de costumbre, las primeras reacciones han sido una política de cuarentena, cierre de las fronteras, aislamiento de los enfermos, prohibición de aglomeraciones públicas y restricción de los desplazamientos. Los responsables de la higiene pública percibieron rápidamente que estas medidas eran ineficaces, pero las prescribieron igualmente "con la intensión loable y bien fundada de apaciguar la ansiedad pública" (Payne, 1955, p. 394).

Los epidemiólogos mostraron el cambio progresivo del comportamiento de la poliomielitis desde finales del siglo XIX. El factor decisivo para la gravedad de la enfermedad era un cambio de los grupos de edades afectadas, de tal modo que, por lo menos en lo que atañe a la poliomielitis, las medidas de higiene, que alejaban las fuentes de infección para el niño en la primera infancia, parecían haber hecho más mal que bien. Burnet (1940) parece haber sido el primero en subrayar la importancia epidemiológica de la evolución general de la edad de las enfermedades. Por consiguiente, en los países que gozaban de buenas condiciones higiénicas, la infección era menos frecuente, pero la enfermedad era más grave. Era inquietante pensar que el mejoramiento del estado sanitario y de higiene general había eliminado prácticamente, en muchas partes del mundo, un gran número de enfermedades infecciosas, pero, al mismo tiempo, había creado las condiciones de una nueva afección epidémica grave. Esta nueva epidemia era considerada como el resultado de los efectos nefastos de nuestrainterferencia con los procesos naturales. Cuanto más eficaz era la aplicación de las medidas sanitarias, más se disminuía el riesgo de una infección natural inmunizante. 
La infección primaria en las personas sería entonces retardada y cuando se producía, lo que era casi inevitable, los efectos tenían tendencia a ser más graves. Así pues, parecía que, en lo que tiene que ver con la poliomielitis, las medidas de higiene eran realmente indeseables, conclusión a la cual ya se ha llegado por los estudios históricos. (Payne, 1955, p. 398)

En 1953, la Tercera Asamblea Mundial de la Salud abordó el problema y subrayó fuertemente el interés que tenía para dar directivas internacionales sobre las medidas que se debían tomar para prevenir la propagación de la poliomielitis. En esta ocasión, fue creado un comité de expertos que tuvo su primera sesión en Roma, del 14 al 19 de septiembre de 1953, después del Primer Congreso Internacional de Microbiología. Su primer informe, publicado por la OMS en abril de 1954, mostraba la necesidad de la creación de un programa internacional de lucha contra la epidemia.

Los resultados de la acción internacional contra la epidemia de poliomielitis fueron positivos, en particular, gracias a la constitución de centros internacionales para la identificación de las cepas, la difusión de las informaciones epidemiológicas y vacunas eficaces. La inmunización contra la poliomielitis produjo un cambio de dirección en la actividad higiénica: en vez de defender una población frente a un virus, apuntaba a la diseminación de un virus de débil virulencia con el objetivo de recrear las condiciones que reinaban a comienzos del siglo XIX. Para hacerlo, era preciso administrarles a todos los niños de pecho una pequeña dosis de virus vivo no atenuado y hacer lo necesario para que el virus fuera ampliamente difundido y que nadie escapara a la infección primaria precoz y a las infecciones ulteriores repetidas que reforzarán la inmunidad, produciendo así el proceso natural de inmunización.

La epidemia de poliomielitis fue una lección de un alcance general que, sin duda alguna, no fue bien aprendida: "Cualquier perturbación en gran escala de la ecología de los procesos naturales puede tener como consecuencia efectos secundarios inesperados y con frecuencia lamentables" (Payne, 1955, p. 398).

\section{La emergencia de nuevas epidemias}

La experiencia trágica de la epidemia de sida ha suscitado el temor de ver aparecer otras formas de enfermedades infecciosas que podrían tomar una expansión catastrófica. En el pasado, solo las grandes pandemias de peste y sífilis han tenido consecuencias sociales, comportamentales y políticas de la misma envergadura que la aparición del sida. Los medios científicos y las autoridades de salud pública nacionales e internacionales han sido entonces conscientes de la posibilidad de que puedan aparecer otras nuevas enfermedades. No solo el cine y la literatura, sino también los medios científicos y las organizaciones 
sanitarias internacionales se han planteado claramente el problema. Se han dedicado conferencias a los "virus emergentes" (Morse, 1993) y la OMS ha creado una nueva división para desarrollar políticas de salud pública y para hacer frente a la emergencia de nuevas enfermedades.

El cambio de medio natural, el trastorno de la vida social y, paradójicamente, los éxitos de la medicina han creado situaciones completamente nuevas. Ilustran un proyecto de reglamento sanitario internacional propuesto por Robert H. Black, profesor de medicina tropical en la Universidad de Sydney y David J. Sencer, exdirector del CDC de Atlanta, quienes tenían una experiencia única de la aplicación práctica del Reglamento anterior. Ambos autores escriben:

Contrariamente a lo que se había hecho antes, nos esforzamos por enunciar principios generales antes que describir medidas precisas para actuar contra tal o cual enfermedad. En efecto, las técnicas modernas en pleno desarrollo condujeron al descubrimiento de enfermedades desconocidas todavía en la actualidad. (Black y Sencer, 1978, p. 472)

En efecto, los dos últimos decenios del siglo $\mathrm{XX}$ han visto aparecer un conjunto de nuevos tipos de patógenos. Las enfermedades de los legionarios, la fiebre de Lassa (Nigeria), la fiebre hemorrágica del Ébola y de Marburg, son solo los principales ejemplos de una larga lista de enfermedades cuya naturaleza o manifestaciones clínicas muestran nuevos caracteres. Además, después del descubrimiento de los retrovirus, han aparecido nuevos campos conceptuales, como los viroides (virus "desnudos") y los priones, formas proteicas patológicas capaces de transformar las proteínas normales. Son los agentes responsables de las encefalopatías espongiformes, sobre todo el Kuru de los indígenas de Nueva Guinea, transmitidos por el canibalismo ritual, la enfermedad de CreutzfeldJacob debida a las acciones médicas (intervenciones neuroquirúrgicas y uso de la hormona del crecimiento) y la enfermedad de la "vaca loca" debida al paso en las vacas de un agente presente desde hace más de un siglo en los corderos.

Así pues, se interroga sobre la naturaleza de estas nuevas epidemias y sobre los medios de prevenirlas.

\section{El concepto de enfermedad emergente}

Una enfermedad se puede considerar como nueva o emergente en los siguientes casos que expone Grmek (1993, pp. 281-296):

1. Imposibilidad para la mirada médica de conceptualizar la enfermedad en tanto entidad nosológica.

2. Cambio cualitativo o cuantitativo de las manifestaciones clínicas. 
3. Introducción a partir de otra población.

4. Introducción a partir de una población animal.

5. Aparición de un agente patógeno verdaderamente nuevo a causa de: a) mutación, b) recombinación y c) variación de la virulencia del germen.

En los tres primeros casos, se puede definir como nueva una enfermedad que no existía en ninguna población humana en tanto que entidad clínica distinta. En los casos 3 y 4, la enfermedad existía y era conocida, pero ha sobrepasado sus límites geográficos o biológicos.

La clasificación puede ser difícil. Un caso histórico muy conocido de esta dificultad lo da la primera pandemia de cólera que azotó a Europa entre 1829 y 1837. El cólera podía ser definido como una nueva enfermedad, porque no existía en Europa y fue introducida a partir de la India. Así pues, sería una pandemia producida por el rebasamiento de barreras geográficas y la invasión de nuevas poblaciones por el germen. Pero este caso se debe considerar, además, como una nueva enfermedad strictu sensu, si se tiene en cuenta que la primera epidemia comenzó en 1817 en la India y era probablemente el resultado de una recombinación genética entre bacterias diferentes.

En la mayoría de los casos, no se trata de enfermedades verdaderamente nuevas, sino más bien de enfermedades que emergen en un momento dado en una población dada y de enfermedades reemergentes, es decir, enfermedades que habían existido antes y habían prácticamente desaparecido, pero que reaparecen con una forma más grave por causas sociales o ecológicas, como por ejemplo la reemergencia de epidemias de paludismo a causa de las transformaciones agrícolas en la Amazonía o de la difteria en algunos países debido al derrumbamiento de los sistemas de salud o aún los accesos de la tuberculosis a causa del estado de inmunodepresión provocado por el sida.

Un caso paradigmático para la discusión de las nuevas enfermedades lo da las pandemias de influenza, una enfermedad muy antigua, pero siempre nueva, que se presenta con ciclos epidémicos regulares. Esta enfermedad es causada por tres tipos de virus (A, B, C). Los virus influenza del tipo A, los más importantes desde el punto de vista de la epidemiología y los más peligrosos en términos de mortalidad, son designados según sus antígenos de superficie, la hemaglutinina $(\mathrm{H})$ y la neuraminidasa $(\mathrm{N})$. Cada cepa será entonces caracterizada por los subtipos de antígenos, por ejemplo, H1N2. El virus de la gripa tiene la capacidad de modificar muy fácilmente su estructura y composición genética, lo que le permite eludir las defensas inmunológicas gracias a las mutaciones y, sobre todo, a la recombinación y el reordenamiento de las diferentes partes de su material genético. Los virólogos hablan de genetic drif (deslizamiento) 
por variaciones de pequeña envergadura, en el interior de un mismo subtipo y de genetic shift (desplazamiento) para variaciones mayores, recombinaciones. La influenza es una enfermedad siempre nueva, aun cuando sus formas clínicas parecen ser permanentes, lo que permite establecer su presencia ya en el siglo XVI. El problema fundamental que se les plantea a los epidemiólogos y a los responsables de la salud pública es prever la emergencia de una cepa verdaderamente nueva de virus, de la del germen que provocó la pandemia de la gripa española en 1918-1919, pandemia que dejó setenta y cinco mil decesos en Suiza y veinte millones de muertos en el mundo, es decir, el 1,5\% de la población mundial.

El caso de la gripa es además paradigmático por el análisis de las medidas que se deben tomar. En efecto, la colaboración internacional ha hecho sus pruebas sobre todo en este campo y los éxitos reportados se deben, en particular, a la constitución de centros internacionales para la identificación de cepas, la difusión de informaciones, los servicios de epidemiología y la difusión rápida y suficientemente vasta de las vacunas.

\section{Nuevas enfermedades y equilibrios ecológicos}

En resumen, hay tres fuentes verdaderas de emergencia de una nueva enfermedad infecciosa:

1. La evolución de novo de un nuevo agente patógeno o, más precisamente, la evolución de una cepa variante.

2. El paso de un germen de una especie a otra, en particular de una especie animal al hombre.

3. El importante aumento de la difusión de este agente más allá de las fronteras tradicionales en las cuales existía en un equilibrio "con débil ruido", es decir, con una incidencia cuantitativamente limitada.

El primer factor es relativamente poco importante, aun cuando la gran variabilidad del virus está en la base de algunos acontecimientos catastróficos en el pasado. La mayoría de las grandes epidemias del pasado y de las enfermedades emergentes actuales resultan más bien de lo que el virólogo Steven Morse ha denominado la "circulación viral", es decir, el paso de agentes patógenos verticalmente a través de diferentes especies y horizontalmente a través de diferentes poblaciones de la misma especie. Así pues, se trata simplemente de antiguos virus conquistando nuevos territorios.

La epidemiología del sida muestra que las actividades y el comportamiento humanos pueden ser la causa determinante de la diseminación de un nuevo agente 
patógeno, o más bien de una cepa más virulenta y que el hombre es el más importante factor de cambio. La epidemia de sida ha sido una importante señal que recuerda la exigencia de tener en cuenta constantemente que las poblaciones humanas viven en un equilibrio precario con el contexto ecológico. Por su actividad, el hombre crea nuevas situaciones que se pueden volver inestables. El desarrollo de las actividades médicas está entre los factores que han producido la emergencia de nuevas enfermedades infecciosas (transfusiones, inyecciones, mejoramiento de las condiciones de higiene, como en el caso paradójico de la poliomielitis). En la totalidad de estos casos, los epidemiólogos y virólogos piensan que el agente causal de la enfermedad estaba presente incluso antes de que la epidemia se manifestara y que su emergencia se debe a factores sociales y ecológicos. La mayoría de las epidemias del pasado solo se pueden comprender en un contexto ecológico. Las investigaciones históricas y epidemiológicas han mostrado que una gran parte de las emergencias de enfermedades estaban vinculadas directamente con actividades humanas que cambiaban el contexto ecológico: agricultura intensiva, migración de la población, deforestación, irrigación, contacto con nuevos mundos (como las catástrofes sanitarias que siguieron al descubrimiento de América).

Todas las asociaciones virus/hospedero tienen umbrales que determinan la posibilidad para un virus de propagarse en una población dada y luego "emerger" y permanecer allí en un equilibrio más o menos estable (May, 1993, pp. 58-68). Estos umbrales dependen de la densidad y los comportamientos de las poblaciones hospederas; cambian en la historia y en el espacio siguiendo los cambios ecológicos, los movimientos de las poblaciones, los cambios culturales y comportamentales.

Como lo ha hecho observar Lederberg (1993, pp. 3-9), la historiografía de las enfermedades endémicas es uno de los últimos refugios del creacionismo, pues los gérmenes responsables parecen aparecer ex nihilo, en vez de ser el resultado de un cambio dinámico de una situación preexistente, de su evolución biológica y social. Durante una conferencia sobre las enfermedades emergentes en Washington en 1989, este autor había recordado la introducción del virus de la mixomatosis en Australia, que había producido una mortalidad inicial del 99, $8 \%$ en la población de conejos, reducida al $20 \%$ de su tamaño antes de la introducción de la "nueva enfermedad". Sobre la historia de la mixomatosis véase Fenner y Fantini (1999). Sobre esta base Lederberg (1993) había planteado

la pregunta de saber si la sociedad humana podría sobrevivir si fuera reducida a solo algunos porcentajes de sobrevivientes, en una playa. ¿Se podrían organizar en algún nivel cultural más elevado que el de los conejos? Y, reducidos a esto, ¿podrían ser competitivos con relación a los canguros? (pp. 3-9) 
Así pues, Lederberg sugiere ver las pandemias de enfermedades infecciosas como un fenómeno natural permanente y recurrente e interpretarlas como un resultado de la coevolución darwiniana entre los gérmenes y las poblaciones humanas.

\section{Las paradojas de una politica de previsión de la emergencia de enfermedades infecciosas}

Frente a la posibilidad siempre presente de nuevas enfermedades infecciosas, se ha subrayado la necesidad de una vigilancia y una estrategia para anticipar y caracterizar la emergencia de nuevos agentes patógenos o de nuevos accesos epidémicos de enfermedades conocidas. En efecto, los conocimientos biomédicos adquiridos permiten la elaboración de predicciones sobre la posible emergencia de una nueva enfermedad infecciosa o sobre la reemergencia de una enfermedad epidémica antigua, una especie de ecological and technological forecasting [previsión ecológica y tecnológica] sobre los cambios de equilibrios entre las poblaciones humanas y sus agentes patogénicos.

El informe del Committee on Emerging Microbial Threats to Health, publicado en 1992, propone la creación de un sistema global y completo de vigilancia contra las enfermedades infecciosas (Institute of Medicine (US) Committee on Emerging Microbial Threats to Health, Lederberg, Shope y Oaks, 1992, pp. 6-7). Sin embargo, esta actividad predictiva (o por lo menos de observación de nuevas entidades) necesita de centros de investigación y una organización de vigilancia internacional de una calidad científica muy alta. Por ejemplo, es evidente que la rápida identificación clínica y la caracterización epidemiológica del sida ha sido posible únicamente gracias a la existencia de un centro altamente eficiente para la vigilancia epidemiológica como los Centers of Diseases Control de Atlanta (Etheridge, 1991).

Esta política de vigilancia sobre las nuevas enfermedades, necesariamente fundada en una vasta cooperación científica y sanitaria, precisa de un excedente de investigación fundamental y aplicada, a causa justamente de la novedad, para la identificación clínica de la nueva patología, la vigilancia epidemiológica, el diagnóstico y la descripción científica del agente patógeno y, en fin, para la adopción de medidas profilácticas. Esto constituye una paradoja, pues esta calidad científica no existe allí donde la vigilancia se debería establecer, es decir, en las zonas particularmente expuestas al riesgo de emergencia de nuevas enfermedades. El problema central para la salud internacional continúa siendo la realización de una organización sanitaria eficaz en cada país.

A comienzos del siglo XX, Calmette (1911, p. 32) había afirmado que las medidas de cuarentena o restrictivas de la libertad de circulación de los pasajeros y las mercancías eran ilusorias en la lucha contra las enfermedades transmisibles, pues el aislamiento de los portadores de gérmenes en las fronteras "es algo 
financiera, práctica y científicamente irrealizable por completo". Sobre esta base, Calmette (1911) llegaba a la conclusión de que era indispensable renunciar a la ambición de resolver el problema aislando a los países occidentales:

Creo que será necesario resolvernos a renunciar a esto deliberadamente, al punto de vista internacional, y reemplazar estas medidas por una organización sanitaria en cada país, suficientemente perfecta para asegurar la detección de los primeros casos sospechosos, el diagnóstico tanto precoz como posible de los primeros casos comprobados y un buen aislamiento, así como una desinfección perfecta del enfermo y de todo lo que lo ha rodeado. (p. 29)

La convención sanitaria de 1903 preconizaba la realización de una fase perfecta de la política sanitaria que unía la implementación del sistema de lucha contra las enfermedades infecciosas exóticas con el descubrimiento precoz y el aislamiento inmediato del primer caso de una enfermedad, objetivo que se busca también en la actualidad para las nuevas enfermedades infecciosas. Como lo había observado Rocco Santoliquido (1911), el primer presidente de la Oficina Internacional de Higiene Pública, "tal perfección, que se puede bien denominar ideal, sin duda, solo es realizable en algunos casos excepcionales y después de circunstancias igualmente excepcionales" (p. 69). El objetivo era aproximarse cada vez más a esta perfección ideal, lo que todavía continúa siendo en la actualidad el objetivo fundamental de la colaboración sanitaria internacional frente a la emergencia de nuevas enfermedades infecciosas.

\section{Referencias}

Anderson, R. M. y May, R. M. (1992). Infectious diseases of humans. Dynamics and control. Oxford University Press.

Beveridge, W. I. B. (1977). Influenza: The last great plague. Prodist.

Black, R. H. y Sencer, D. J. (1978). The Long-Term Future of the International Health Regulations. WHO Chronique, 32, 437-440.

Burnet, M. (1953). The future of medical research. Lancet. 261(6751), 103-108. https://doi.org/10.1016/ s0140-6736(53)90826-5

Burnet, F. M. (1940). The Action of Certain Surface-Active Agents on Viruses. Australian Journal of Experimental Biology and Medical Science, 18(2), 141-150.

Calmette, A. (1911). Procès verbaux des séances du Comité permanente de l'OlHP.

Etheridge, E. W. (1991). Sentinel for health. A history of the Centers for Disease Control. University of California Press.

Fenner, F. y Fantini, B. (1999). Biological Control of Vertebrate Pests. The History of Myxomatosis, an Experiment in Evolution. CABI Publishing. 
Grmek, M. D. (1969). Préliminaires d'une étude historique des maladies. Annales Économies, Sociétés, Civilisations, 24(6), 1473-1483. https://www.persee.fr/doc/ahess_0395-2649_1969 num_24_6_422182

Grmek, M. D. (1989). Histoire du SIDA. Début et origine d'une pandémie actuelle. Payot.

Grmek, M. D. (1993). Le concept de maladie émergente. History and Philosophy of the Life Sciences, 15(3), 281-296. Enlace doi

Howie, J. W. (1968). Infectious disease, does it still matter? Public Health, 82(6), 253-268.

Hoyle, F. y Wickramasingh, H. C. (1979). Disease from space. Dent \& Sons Ltd.

Institute of Medicine (US) Committee on Emerging Microbial Threats to Health, Lederberg, J., Shope, R.E. y Oaks S.C. Jr. (eds.) (1992). Emerging infections. Microbial threats to health in the United States. National Academies Press.

Lederberg, J. (1993). Viruses and Humankid. Intracellular Symbiosis and Evolutionary Competition. En S.S. Morse (ed.), Emerging Viruses (pp. 3-9). Oxford University Press.

May, R. M. (1993). Ecology and Evolution of Host-Virus Associations. En S.S. Morse (ed.), Emerging Viruses (pp. s.n). Oxford University Press.

Morse, S.S. (ed.) (1993). Emerging Viruses. Oxford University Press.

Organisation Mondiale de la Santé (1955). La poliomyélite. Série de Monographies, Organisation Mondiale de la Santé, (26).

Payne, A. M. M. (1955). Les mesures de santé publique dans la lutte contre la poliomyélite. Série de Monographies, Organisation Mondiale de la Santé, (26), 393-418.

Santoliquido, R. (1911). Procès-verbaux des séances du Comité permanent de l'OIHP.

Sontag, S. (1990). Illness as metaphor. AIDS and its metaphors. Anchor Books.

Sontag, S. (1996). La enfermedad y sus metáforas. El sida y sus metáforas. Taurus.

Stowman, K. (1947). Epidem. vital. Statist. Rep.

Weekly Report. (1981). Centers for Disease Control: Pneumocystis pneumonia. Morb. Mortal. 